\title{
ESTUDOS SOBRE RELIGIÃO NA PÓS-GRADUAÇÃO EM CIÊNCIAS SOCIAIS DA UERJ: O CONTEXTO DO RIO DE JANEIRO E A PRODUÇÃO RECENTE
}

\author{
Cecília Mariz ${ }^{1}$
}

Clara Mafra $^{2}$

\begin{abstract}
Resumo: Neste artigo descrevemos o grupo de pesquisa em religião do Programa de Pós-Graduação em Ciências Sociais da UERJ: sua formação, o perfil de seus membros, sua produção recente e as dissertações e teses que foram orientadas pelos membros do grupo. Para contextualizar esse grupo, realizamos uma breve retrospectiva histórica dos estudos da religião no Rio de Janeiro discutindo o papel que organizações não governamentais tiveram ao incentivar a pesquisa sobre religião, destacando o Instituto de Estudo da Religião (ISER), e o papel das pós-graduações.
\end{abstract}

Palavras-chave: Ciências Sociais, Religião, ONG, pós-graduação, ISER.

Abstract: In this article we describe the research group on religion of the PostGraduate Social Sciences Program at UERJ: its setting up, profile of the members, recent production and the dissertations and theses supervised by its members. In order to contextualize this group, first we did a short retrospective historical overview of the study of religion in Rio de Janeiro discussing the role that non-governmental organisations had in encouraging research on religion, highlighting the Institute of the Study of Religion (ISER), and the role of post-graduate programmes.

Keywords : Social Sciences - Religion - NGO - Post-Graduation Program ISER.

${ }^{1}$ Professora do Departamento de Ciências Sociais e do Programa de Pós-Graduação em Ciências Sociais da Universidade Estadual do Rio de Janeiro.

2 Professora do Departamento de Ciências Sociais e do Programa de Pós-Graduação em Ciências Sociais da Universidade Estadual do Rio de Janeiro.

Debates do NER, Porto Alegre, ANo 8, N. 11, P. 21-48, jAn./Jun. 2007 
Berço da umbanda e da Igreja Universal, o Rio de Janeiro se destaca no Brasil não apenas como gerador de religiões, mas também pela produção de dados e análises sobre esse fenômeno. ${ }^{3}$ Dentre os diversos programas de pósgraduação em ciências sociais desse Estado, ${ }^{4}$ o da Universidadedo Estado do Rio de Janeiro (UERJ), tema deste nosso artigo, é um dos mais recentes, mas o que atualmente mais reúne professores pesquisando religião. Antes de nos voltarmos para a análise do grupo, da sua produção recente e das dissertações e teses que tem orientado, realizamos uma breve retrospectiva histórica ${ }^{5}$ dos estudos da religião no Rio de Janeiro. Inicialmente, discutiremos o papel que as organizações não governamentais e seus projetos sociais tiveram no incentivo da pesquisa sobre religião, destacando o Instituto de Estudo da Religião (ISER), desde que quase todos os membros desse grupo de pesquisa em um momento ou outroestiveramenvolvidos com ele.Com essaanálise, esperamos oferecer subsídios para melhor entender as ênfases nas questões pesquisadas, trajetórias e parcerias de seus membros.

\section{CIÊNCIAS SOCIAIS E RELIGIÃO NO RIO DE JANEIRO: UMA PERSPECTIVA HISTÓRICA}

Parao visitantedesavisado, pareceestranha a grande concentração, ainda hoje, de grupos de estudo da religião nas ciências sociais das universidades fluminenses. Muito facilmente, um convidado estrangeiro que tenha se dedicado, por exemplo, ao campo das religiosidades de origem afro, pode se

\footnotetext{
${ }^{3}$ Em sua tese sobre os estudos da religião no Brasil, Sonia Reyes Herrera (2004, p. 284-285) observa a concentração de grupos de pesquisa em Antropologia da Religião no Rio de Janeiro.

${ }^{4}$ Estamos nos referindo ao Museu Nacional (Antropologia), IUPERJ (Sociologia e Ciência Política), os programas da UFRJ, da UFF, UFRRJ (CPDA), PUC (Ciências Sociais) e da UENF.

${ }^{5}$ Agradecemos a Waldo César, Otávio Velho e Patrícia Birman, que através das entrevistas que nos concederam nos ajudaram a contar essa história. Agradecemos também aos bolsistas do CNPq Paulo Victor Leite Lopes, Janine Targino, Patrícia Silveira e Rosiane Silva, que transcreveram as gravações.
} 
ver rodeado de "especialistas no assunto", todos de universidades e centros de pesquisa da região, tendo que responder comentários e críticas nas mais diversas tradiçõesintelectuais (desde um estrutural-funcionalismoweberiano ou durkheiminiano, um interacionismo-simbólico, um pós-estruturalismo, um aporte mais focaultiano ou performático da cultura). O que teria provocado esta estranha atração, perguntou intrigado um destes visitantes, por um tema que, para além de toda revisão crítica, segue à margem do pensamento majoritário ocidental?

Parece-nos que esse interesseespecial surgiu exatamentena passagemdos anos 1970para os anos 1980, quando colidemos experimentosde intervenção social organizados pelas igrejas e pelos partidos de esquerda, e sua ênfase na produção junto com as "bases", voltados para uma "educação popular", com as dinâmicas de formação dos cursos de pós-graduação, fortemente direcionados para a produção de abordagens etnográficas, valorizando o estudo do "familiar". Sem ter sido planejado, os estudos sobre religião no Rio de Janeiro contemporâneo acabam por se revitalizar nesta colisão de perspectivas, sem o quê, a produção intelectual seguiria duplamente constrangida: ora por um receio de se colocar "sobre uma torre de marfim" - como atribuem alguns militantes dos centros de pesquisa universitários -, ora na aversão à produção de um conhecimento excessivamente interessado, portanto, "oportunista e intervencionista", acusação que corre no sentido contrário.

Nas próximas páginas, vamos rememorar algumas das inquietações que acompanharam a formação dos primeiros núcleos de pesquisa sobre religião no Rio de Janeiro, alocados fora (mas não longe) das igrejas e das universidades, comoo Instituto de Estudoda Religião (ISER), o Centrode Estatística Religiosa e Investigações Sociais (CERIS) e o Instituto Brasileiro de Desenvolvimento Social (IBRADES). ${ }^{6}$ Em seguida,nos voltaremos para a formação das primeiras pós-graduações, ainda na década de sessenta, e seu impacto nas

\footnotetext{
${ }^{6} \mathrm{O}$ papel das ONGs no estímuloà pesquisa, especialmente o ISER no caso da religião, já tem sido destacado por vários autores. Ver, entre outros, Oro (1993), Mariz (1993), Camurça (2001) e Reyes Herrera (2004).
} 
novas condições da produção do ensino e da pesquisa. Por fim, indagaremos sobre a emergência de um outro fazer acadêmico em função deste processo regional, levando-se em conta o sucesso das universidades enquanto lócus da produção de ensino e pesquisa nas ciências sociais no Brasil.

\section{A EXPERIÊNCIA MILITANTE DAS ONGs}

Segundo Leilah Landim (1998), no Brasil, o ambiente de formação das primeirasorganizações não governamentais foi marcadopor grande informalidade, necessária invisibilidade e forte ênfase nas relações pessoais. Com a ditadura, muitas das pessoas que atuavam no campo da educação no pré-64, religiosas ou não, acabaram tendo que restringir suas atividades e se dedicar a um circuito semi-clandestino de competências. Trata-se de um conjunto de pessoas com passagem nos trabalhos de "base" nos partidos e organizações, ou com circulação nas novas pastorais, em função da Teologia da Libertação, ou com inserçõesno Conselho Mundial de Igrejas e demais órgãos ecumênicos. Entre u m emprego e ou tro, elas acabavam realizando u ma "assessoria" aqui, "fazendo um trabalho de base" ali, "promovendo um trabalho de educação popular durante anos", ganhando, assim, uma competência de mediação dita "comprometida" ou "a serviço" das camadas populares. Ao contrário dos pares acadêmicos,este tipo de competênciaera formada na prática, em meio à ação e convivência com "as bases".

Melhor dito, ser "assessor" neste contexto significa atuar como mediador entre as "bases", numerosas e culturalmente distantes, e os agentes externos, raros e de difícil acesso. Em muitos casos, a ponta que vinha de uma Europa rica e reconstruída, chegava com um enorme afã reformador. Neste caso, fazer mediação como representante dos trópicos podia implicar um trabalho de moderação, modelamento, ajuste de uma certa vontade caridosa mas autoritariamente confiante de si.

Naquele tempo, existiam muitas organizações que trabalhavam com tecnologia, intervenção tecnológica, produção de tecnologia. Isto foi uma moda nos anos 70. Por exemplo, no altiplano boliviano, 4.000 metros de altitude, preparar 
um café, levava meia hora. Como o ar era rarefeito, o oxigênioqueimava muito rápido e a chama não durava muito. Aparecu ali um grupo de produção de tecnologia que achou que iria resolver o problema. $\mathrm{O}$ grupo trouxe uns fogões com um buraco certinho para o tamanho da panela, com isto todo o calor produzido eraretido, e o tempo de cozimento diminuía drasticamente. À primeira vista, aquilo parecia fantástico! Mas acontece que "solução do problema" não agradou aos maridos. Eles diziam: "o quê as mulheres vão fazer depois do fogão?! Elas têm de trabalhar!" (Waldo César, entrevista em novembro 2006)

Alguns projetos chegavam pela primeira vez em alguns rincões do Brasil e da América Latina, alcançando populações completamente imersas nas cadeiasde lealdade locais.Em geral,os projetos eram desenhados para deslocar relações de dominação cristalizadas ao longo do tempo. Junto com o possível e previsível deslumbre de abertura de mundo das "bases", seguia-se, muito corriqueiramente, o choque cultural. Os desarranjos e emergência de novos conflitos demandavam continuidade no acompanhamento:assim, os projetos eram renovados, não uma, mas algumas vezes,reunindodurante anos a mesma "base" e os mesmos "assessores". Com o correr dos anos, com mais e mais projetos desenvolvidos e em desenvolvimento, viu-se a necessidade de se produzir encontros entre os mediadores-assessores.

Um dia meu coordenador pediu: "eu quero que vocês reúnam todas as organizações que estão trabalhando nesse campo [a América Andina]”. Foi uma coisa fantástica: gente que fazia o trabalho ao lado, ou o mesmo trabalho em outra região, se descobriu, reconheceu dificuldades comuns, participou de um debate que tomourumos inesperados porque as pessoas estavam se descobrindo. (Waldo César, entrevista em novembro 2006)

O ISER ${ }^{7}$ foi se formando, como era comum na época, como "grupo de amigos”, porém, um grupo largo, composto por pelo menos três diferentes

${ }^{7}$ O Instituto de Estudos da Religião teve origem no ISET (Instituto Superior de Estudos da Religião), que era composto basicamente por evangélicos ecumênicos, ligados ao Conselho Mundial de Igrejas, emuma atuação ao longodos anos 50 e 60. O ISER foicriado em Campinas em 1970, e foitransferido para o Riode Janeiroem 1973(Novaes, 1997; Reyes Herrera,2004).

Debates do NER, Porto Alegre, ANo 8, N. 11, P. 21-48, JAN./Jun. 2007 
circuitos. Um círculo um tanto expressivo de cristãos ecumênicos, muitos de origem protestante, que depois migraram para a Universidade. Encontramos aí Rubem Alves (primeiro presidentedo ISER), Waldo César (com passagem no Conselho Mundialde Igrejas), Richard Shaull (pastor Metodista), Rubem César Fernandes(que retornava do exílio em 1974). Um circuito católico, de intelectuais da Igreja”, como Alberto Antoniazzi, Francisco Cartaxo Rolim, Pedro Ribeiro de Oliveira.Mais um circuito acadêmicoestritosenso. O método era o improviso; a sustentação,a informalidade; o objetivo, um tanto vago.

O ISER reunia pesquisadores de religião desde o início dos anos 70, cujo presidente era o Rubem Alves. A sede era na casa do Rubem, que era professor de filosofia da UNICAMP. Nos anos 70, o ISER se reunia duas vezes por ano. Era um conjunto de pesquisadores, de vários lugares do país, que se encontrava periodicamente. Geralmente em um fim de semana: organizava-se um seminário, cada vez escolhia-se um tema, as pessoas traziam um paper e se encontravam. Era uma rede de pesquisadores e uma rede de amigos. As duas coisas se combinavam. (Rubem César Fernandes em entrevista para Regina Novaes, 1997, p. 8)

Nosanos 1980, no Riode Janeiro,o ISERampliasua redede pesquisadores que eram tambémprofessores e estudantes de pós-graduações. Diferentemente dasdemais ONGs,o ISER, ao ladode projetosintervencionistas, passa a propor pesquisas estritamente acadêmicas tornando-se nesse período um dos centros mais importante de referência em religiãonas ciênciassociais no Brasil.Destacamos nessa época o grupo de pesquisa sobre catolicismo, coordenado por PierreSanchis, que reuniaampla rede de professoresfiliados a universidades de todas as partes do Brasil e desenvolveu vários projetos apoiados pelo $\mathrm{CNPq}$ produzindoartigos e livros (ver por exemplo Sanchis, 1992 a, 1992 b, 1992c) de repercussão na academia. Desse grupo, participaram nomes como Ralph Della Cava, Carlos Rodrigues Brandão, Paula Montero, Regina Novaes, Raymundo Heraldo Maués, Francisco Cartaxo Rolim, Pedro Ribeiro de Oliveira, Ana Maria Doimo, Carmem Cinira Macedo, José Ivo Follmann. Tambémpodemosconsiderar comoresultado desseISER comperfil acadêmico os projetos de pesquisa, coordenados por Rubem César Fernandes, que 
resultaram no Censo Institucional Evangélico de 1992 (s/d) e no livro Novo Nascimento - os evangélicos em casa, na rua e na cidade (1994).Ambos tiveram impacto na reflexão sobre religião no país, justamente porque conseguiram somarrigor científico, qualidade acadêmica e inovação no modode cooperação entre pesquisadores.

Na década de 1990, o ISER sofre crises que resultam em sua subdivisão em várias ONGs menores em 1995. Nesse momento, a Equipe de Assessoria às Organizações de Base e Entidades Religiosas, que tinha sido criada no ISER em 1982, se torna uma organização não governamental autônoma: o ISER/Assessoria.

Embora com marcas próprias, ISER e ISER/Assessoria compartilham várias similaridades entre si, e também com outras ONGs, por gerenciar verbas vindas do exterior, por apoiar projetos de assessoria e pesquisa a movimentos sociais e religiosos, e também por se identificar com determinadas propostasde intervenção social.Entram aqui o CERIS, cujas atividades foram encerradas em 2007, que se singularizava por ser responsável pelo Anuário Católico tendoassim vínculos com a CNBB; o IBRADES, vinculado aos jesuítas. Anos mais tarde foi formado o KOINONIA.

Para os objetivos deste artigo, queremos sublinhar três características que atravessam estas organizações:

1. Criam espaços que são menos de divulgação de um certo saber ou tecnologia social,como aconteœ nos fórunscriados pelo Estadoe pela Igreja,e mais de experimentação na interlocuçãoentre mediadoresnacionais e estrangeiros, "assessores-pesquisadores" e suas "bases". Este espaço está atravessado por uma promessa de formação de uma cultura cívica ampliada, porém, com um forte interesse em "mobilizar" para "qualificar" as "bases", e/ou atuando com uma grande necessid ade de "convencimento do financiador", aspectos que tendem a desembocar em uma certa incapacidade de absorção das diferenças. Anos mais tarde, no artigo "Besta Fera”, Otávio Velho (1987 e 1995) sugere alguns limites desta interlocução. Naquele artigo, Otávio Velho recorda que uma geração de pesquisadores, os quais vão a campo em busca da "resistência popular", parecem incapazes de reconhecê-la em sua dimensão mais sutil e duradoura como, por exemplo, na metáfora da 
"besta fera" e nas inúmeras referências da linguagem camponesa cotidiana a uma cultura bíblica dispersa.

2. Estas organizações nascem na informalidade, baseiam-se em redes de lealdade e de relação pessoal ou religiosa, porém, recusam-se a ser "mais um elemento do sistema". Seu horizonte futuro é o da criação de uma "personalidade pública”, estabelecendo-se, idealmente, comoum centro de referência, de elaboração e de produção de política cultural para um conjunto significativo de interlocutores. Não se trata de transformar a organização em um centro concentrador de recursos e de conhecimento, capaz de repensar uma nação, como seria a expectativa de uma estrutura do tipo partidária, mas também não se quer abrir mão e simplesmente se seguir as "regras do dedão", de busca de satisfação no encontro de soluções sempre situacionais e parciais. Esta expectativa se coloca em vários planos.

3. Como estas organizações não pertenciam ao Estado e não faziam parte do sistema universitário, tiveram, em certos períodos, autonomia e liberdade necessárias para a realização de projetos de cooperação entre instituições gabaritadas, que de outra forma dificilmenteconseguiriam superar as obstruções burocráticas regionais. Devido à sua produção, o ISER ganhou reconhecimento acadêmico, tornando-se membro da Associação Nacional de Pós-Graduação em Ciências Sociais (ANPOCS).

Vale ressaltar, ainda, que a revista Religião e Sociedade se tornou nesse período um meio privilegiado de divulgação da produção acadêmica dos intelectuais que se articulavam através do ISER. Essa revista ajudou a nuclear esses intelectuais e desta forma se transformou em uma referência nesse campo de pesquisa no Brasil e no exterior.Com 30 anos de história, uma das revistas mais antigas do país, Religião e Sociedade tem sua sede no ISER, e é geridapor um comitêde editores, sendo 3 da UERJ, 2 da UFRJ, 1 da UFGRS e 1 da UFMG. Reconhecida como nível 1 Nacional pelo Qualis, com financiamento pelo $\mathrm{CNPq}$ ao longo da sua vida, acumulou, com certeza, a maior concentração de artigos de autores acadêmicos nas áreas de sociologia e Antropologia da Religião no Brasil. 


\section{A EXPERIÊNCIA DA PÓS-GRADUAÇÃO}

A década de 1960 é também o período da formação dos primeiros programas de pós-graduaçãono Brasil. No Riode Janeiro,não sem resistências, veio a se formar um dos primeiros programas de Antropologia, o Programa de Pós-Graduação em Antropologia Social, do Museu Nacional, em 1968. Para romper as amarras de um certo preconceito antiintelectualistaque vigorava inclusive no interior da universidade, o professor Roberto Cardoso de Oliveira procurou uma parceria de fora, do Centro Latino-Americano de Pesquisas em Ciências Sociais (cf. Velho, 2006, p. 11). Os tempos eram outros, a idéia de um futuro favorável à realização de ensino e pesquisa de qualidade não necessariamente desembocava na valorização da academia. Nesse mesmo período, são criadas as pós-graduações em sociologia do IUPERJ (1969) e da UFRJ-IFCS (1968). A Universidade do Estado do Rio de Janeiro,criada na décadade 1960, no entanto,não se integraa esse projeto. Nesse período, seu projeto é exclusivamente o de ensino de graduação.

Nas universidades, a pesquisa sobre religião era desenvolvida especialmente nos programas de Antropologia e tinha como foco quase que exclusivamente as religiões afro-brasileiras. Em 1974, foi defendida a primeira dissertação do Museu Nacional sobre religião, Guerra de Orixá, de Yvonne Maggie. A partir do estrutural-funcionalismo britânico, essa autora rompe com o evolu cionismo de Bastide e com a busca da "pureza" e "africanidade" do candomblé, para analisar a dinâmica concreta dos terreiros e entender como a prática da possessão e mediunidade eram socialmente vividas no Brasil contemporâneo. Yvonne Maggie inaugura, portanto, uma nova perspectiva no estudo dos cultos afro-brasileiros, que reaparece em vários autores da época como Peter Fry, Patrícia Birman, entre outros. Refletindo sobre a bibliografia produzida nesse período, Patrícia Birman (2007) afirma "em lugar de u ma resposta sobre a 'contribuição' que os candomblés dariam para a 'nação', ou sobre as vantagens ou desvantagens dos cultos 'misturados' do ponto de vista da integração dos negros na sociedade, alguns autores passaram a privilegiar o estudo destes cultos por 'eles mesmos', isto é, segundo o que dizem e o que fazem seus integrantes".

Debates do NER, Porto Alegre, ANo 8, N. 11, P. 21-48, JAN./Jun. 2007 
Outro marco entre as primeiras dissertações do Museu Nacional foi Os Escolhidosde Deus, de Regina Novaes, defendida em 1975. Nesse trabalho, a autora acompanha os conflitos e tensões que atravessam uma pequena cidade do interior nordestino, cuja tradição é católica, diante das primeiras conversões de algumas famílias de camponeses ao pentecostalismo. Nesta vertente, estabelece-se um diálogo com os mestres fundadores das ciências sociais - Marx, Weber e Durkheim. A tradição dos estudos de comunidade,herança da Escolade Chicago, e um diálogo com as organizações não governamentais, inspiradas pela Teologia de Libertação e pelos movimentos sociais, conduziam a uma interlocução mais direta com as tradições cristãs.

Observa-se, contudo, que enquanto as ONGs eram mobilizadas pela Teologia da Libertação, a academia e especialmente os programas em Antropologia eram muito pouco afetadas por essa corrente religiosa nas décadas de 1970 e 1980. Da mesma forma, não havia troca entre os estudos das religiões afro-brasi leiras e as pesquisas da ONGs. Esses estudos desenvolvidos na academia não dialogavam com a Teologia da Libertação, e vice-versa, como ressalta Patrícia Birman (entrevista em novembro de 2006). Com efeito, praticamente nada foi produzido sobre a umbanda ou o candomblé pelas ONGs, que tinham mais interesses na possibilidade de "conscientização social" pela via política ou cristã. Mas em outros campos de pesquisa sobre religião, a troca era muito freqüente entre academia e ONGs.

Nesteperíodo, era comuma presença de professores(as) pesquisadores(as) com posições na academia nas diversas disciplinasdas ciências sociais, desenvolvendo pesquisas e projetos diversos nas organizações não governamentais. No campo da pesquisa sobre religião, contudo, essa troca era mais forte com o quadro de professorese alunos de programas de pós-graduação em Antropologia. Em geral, os sociólogos ligados às pós-graduações e às ONGs tinham interesse em outrasáreas de atuação e pesquisa,que não as de estudos da religião.

Devido à hegemoniada abordagemmarxista na maiorpartedos programas em sociologia e ciência política, havia pouca margem para o desenvolvimento de pesquisa em religião. Os sociólogos da religião ativos nas ONGs ou eram professores nas universidades, como Waldo César e Luiz Alberto 
Gómez de Sousa, ou eram professores em universidades onde na época ainda não havia pós-graduação, como Pedro Ribeiro de Oliveira (foi professor da UERJ de 1986 a 1991), e Francisco Cartaxo Rolim (professor da UFF até seu falecimento). Notamos também que a formação doutoral desses professores ocorreu fora do Rio de Janeiro (Luiz Alberto Gómez de Souza na França,Pedro Ribeiro de Oliveira na Bélgica, FranciscoCartaxo Rolim na USP). Antes da década de 1990, era quase impossível estudar sociologia da religião em programa de pós-graduação no Rio de Janeiro. Os que se interessavam por esse tema teriam que procurar a Antropologia. $\mathrm{O}$ quadro teórico hegemônico nos programas de pós-graduação em sociologia era marxista, o que se traduzia em uma relativa indiferençapelo tema da religião nas sociedades contempo-râneas, del egando-o aos especialistas das sociedades não-industriais, especialmente aos antropólog os, que em geral preferiam estudar a religião afro-brasileira. No Brasil, nesse período a Teologia da Libertação inspirava pesquisa e militância em ONGs, mas não nas universidades e programas de pós-graduação, embora por vezes os pesquisadores fossem os mesmos. ${ }^{8}$

Com a crise do marxismo e a posterior queda do muro de Berlim, essa militância se arrefece. Paradoxalmente, as universidades se interessam mais pela religião e as pesquisas nas ONGs entram em crise.

\section{O GRUPO DE PESQUISA RELIGIÃO E MOVIMENTOSSOCIAIS DA UERJ}

Como já foi destacado, pesquisa acadêmica e pós-graduação têm sido projetos inseparáveis no Brasil desde o início de reforma universitária dos

\footnotetext{
8 Já no exterior, há uma sociologia de viés marxista em centros universitários que pesquisavam o o TerceiroMundo.Naépoca, a questãodo desenvolvimento era centralpara a Sociologia, e a pós-graduação em Sociologia do Desenvolvimento em Louvain e o Grupo de Orientação Católica de François Houtart formaram sociólogos preocupados com a religião. Observa-se nesse período que os sociólogos que se preocupavamcom religião eram ou weberianos, como Cândido Procópio e sua escola em SãoPaulo, ou marxistas, com viés da Teologia da Libertação.
}

Debates do NER, Porto Alegre, ANo 8, N. 11, P. 21-48, JAN./Jun. 2007 
finais da década de 1960. O apoio sistemático à pesquisa por órgãos de fomento no Brasil tem ocorrido sempre vinculado à formação de cursos de pós-graduação. No final da década de 1960 e início dos anos 1970, houve um grande incentivo à criação de cursos de mestrado. Lembramos que diferentemente da UniversidadeFederal do Rio de Janeiro, a direçãoda UERJ decide investir em pós-graduação e pesquisa apenas a partir de 1990. O investimento se concentra de início em quatro projetos de pós-graduação. $\mathrm{O}$ de Ciências Sociais é um desses porque nessa área já havia um corpo de mestres e doutores formados pelo Museu Nacional e pelo IUPERJ. Na liderança desse grupo de professores, se destacavam Patrícia Birman, que tanto no seu mestrado e doutorado pesquisou religião afro-brasileira, e também Márcia Leitee SandraSá Carneiro, que na épocaainda não tinhamdoutorado e eram mestres, respectivamente, pelo IUPERJ e PPGAS/Museu Nacional.

Em março de 1994 se inicia a primeira turma de mestrado em Ciências Sociais. Nesse período, os professores permanentes ligados à linha de religião eram apenasPatríciaBirman e Luiz RodolfoVilhena,que cursavao doutorado no Museu Nacional, onde havia também feito seu mestrado.

Com abertura de concursos em 1995, o quadro permanente dos que pesquisam a religiãocresce com a entradade CecíliaMariz (com formaçãoem sociologia, mestreUFPE e doutorado na BostonUniversity)e MárciaContins (mestre pelo PPGAS/Museu Nacional e doutorado pela ECO/UFRJ).

A partir de 1998, projeta-se um curso de doutoramento. Nesse período, a pós-graduação se reorganiza, adota a sigla PPCIS, novos grupos e linhas de pesquisa se formam. A linha de pesquisa em religião, que já havia perdido o professor Luiz Rodolfo Vilhena, falecido tragicamente em acidente em 1997, se amplia passando a se definir como linha de pesquisa em Religião e MovimentosSociais, incorporando as professoras MárciaLeite (que defendeu seu doutorado pelo IFCS em 2000), Rosane Prado (mestre e doutora pelo PPGAS/Museu Nacional). Enquanto Márcia Leite trabalhava com movimentos sociais contra a violência, Rosane Prado desenvolvia trabalhos sobre movimentos ambientalistas.

Em agosto de 1999, a primeiraturma de doutoradoinicia seus trabalhos. Dois novos prof essores ingressam nesse grupo depo is da abertura do 
doutorado. Clara Mafra, mestre pela UNICAMP, e doutora pelo PPGAS/ MuseuNacional, com tese sobre a Igreja Universal do Reino de Deus (Mafra, 2002), e Sandra Sá Carneiro, que foi incorporada à linha depois de defender sua tese de doutorado sobre o caminhode Santiagode Compostela (Carneiro, 2003), no IFCS/UFRJ.

Esse conjuntode professores está registradono diretóriodo CNPq como o grupo de pesquisa Religiosidade no Meio Urbano cujAS líder e vice-líder são Patrícia Birman e Cecília Mariz. Reunindo sociólogos e antropólogos, o grupo explora, segundocertas preocupações e indagações comuns, não apenas a presença,a diversidade e as formas plurais de práticasreligiosas e suas articulações com a vida social, mas também diversas modalidades de movimentos sociais. O livroorganizadopor Patrícia Birman (2003) Religiãoe Espaģo Público oferece um panorama tanto do tipo de produção do grupo até aquele ano, bem como de suas parcerias. No entanto, não pretendemos aqui analisar essa produção nem parcerias, mas apenas apontar para as temáticas trabalhadas pelos professores em suas publicações mais recentes (em geral de 2005 a 2007) e por seus estudantes em suas teses e dissertações. Vale a pena lembrar que, como está explícitona própriaementa do diretóriodo CNPq, esse grupo estuda prioritariamente, mas não exclusivamente, o fenômeno religioso.

O acelerado crescimento do pentecostalismo a partir dos anos 1980 no Brasiltem estimuladoa reflexão de muitospesquisadoresnas ciências sociais. $\mathrm{O}$ grupo da UERJ não é exceção. Todos os membros do grupo já fizeram algum tipo de trabalho nesse campo, mas essa questão tem sido mais analisada por ClaraMafra,Patrícia Birman, Cecília Marize Márcia Contins e seusorientados.

Além de seu livro baseado em sua tese de doutoramento sobre a Igreja Universal em Portugal (Mafra, 2002), Clara Mafra publicou um livro sobre a história dos evangélicos no Brasil (Mafra, 2001), e diversos artigos sobre pentecostalismo no Rio de Janeiro(Mafra, 2007 e Mafra e Swatowiski, 2007) e também em Rondônia (Mafra, 2006), estado brasileiro com maior percentual de evangélicos. Outrasáreas de interessede Clara estão na fronteira entre religião, violência e cidade, tema da parceria em curso com Ronaldo Almeida (CEBRAP/UNICAMP).

Debates do NER, Porto Alegre, ANo 8, N. 11, P. 21-48, JAN./Jun. 2007 
Em seus trabalhos mais recentes, Patrícia Birman (2006) tem enfocado a atuação dos pentecostais na esfera pública e na mídia. Essa autora tem, contudo, grande investimento de pesquisa na religiosidade afro-brasileira (Birman, 2007 e 2005), e ainda em pesquisa sobre a relação religião-espaço público, especialmente no caso dos grupos definidos como "seitas" na sociedade francesa (Birman, 2000, 2005a). Os movimentos sociais que se organizam contra a violência é outro tema de interesse recente dessa professora, como fica claro na publicação do livro $U_{m}$ Mural para a Dorem co-autoria com Márcia Leite (Birman e Leite, 2004).

Embora tenha diversas publicaçõessobre pentecostais, Cecília Mariz em seus trabalhos mais recentes tem se voltado para o catolicismo (Mariz, 2005, 2006; bem como Mariz, Machado, Drogus e Stewart-Gambino, 2005; Machado e Mariz, 2006). O pentecostalismo, contudo, ainda está entre suas preocupações (Machado e Mariz, 2006). Em co-autoria com Vitória Peres, também pesquisou e publicou sobre islamismo (Mariz \& Peres,2007). Além das parcerias com Vitória Peres, da Universidade Federal de Juiz de Fora, e Maria das Dores Machado, da UFRJ, essa professora tem escrito em co-autoria com Marjo de Theije da Vrije Universiteit Amsterdam/VUA (Theije e Mariz, 2008).

Duas são as áreas temáticas destacadas nas produções mais recentes de Sandra Sá Carneiro: as rotas de peregrinações e o ensino religioso nas escolas públicas do Rio de Janeiro. Seu interesse sobre peregrinação surge com sua tese de doutoramento sobre os peregrinosbrasileiros e o caminho de Santiago de Compostela (Carneiro, 2003a e 2003b), e agora se amplia para novas rotas de peregrinação abertas no Brasil (Carneiro, 2004a) e também para o turismo religioso (Carneiro e Freire-Medeiros, 2005) e práticas alternativas de religiosidades (Birman, Leite e Carneiro, 2004; Carneiro, 2004b). Desenvolve a pesquisa sobre novas rotas de peregrinação em parceria com Carlos Steil, da UFRGS. Já em seu estudosobre o ensino religioso, troca com Emerson Giumbelli da UFRJ e com o ISER (Carneiro, 2006).

Paralelamente, mas também de forma inter-relacionada ao seu estudo sobre pentecostalismo, carismáticos e a devoção ao Espírito Santo no catolicismo popular, Márcia Contins (2005a; Contins e Gomes, 2007), tem se 
dedicadoao estudo da questãoétnica, especialmente à negra, tendo publicado tanto sobre pentecostais negros (Contins, 2004b) quanto sobre lideranças negras e ação afirmativa (Contins, 2005b e 2004a). Além da colaboração com José Reginaldo Gonçalves da UFRJ, Márcia Contins faz parecerias com o PACC/CIEC da Escola da Comunicação da UFRJ.

Para Márcia Leite, que tem privilegiado o estudo da violência na cidade, a religião tornou-se um tema importante por estar sendo um recurso de organização social nos movimentos pela paz e cidadania no Brasil (Leite, 2007, 2006b, 2005; Birman e Leite, 2004). A religião, bem como a questão da dádiva (Leite, 2006a), têm lhe interessado muito especialmente no papel que podem desempenhar motivando os atores sociais para a esfera pública. Márcia Leite tem estabelecido parceria com o grupo de pesquisa coordenado por Luís Antônio Machado, no IUPERJ.

Como já foi dito, o tema central das produções de Rosane Prado (2003, 2006ae 2006b)é a questãodo meio ambiente, tema que a autoratrabalha sem deixar de ladoo recorteda religião. Estecruzamentotem permitido colaborações com Patrícia Birman,especialmente porque as duas pesquisadoras têm desenvolvido suas pesquisas de campo na Ilha Grande (ver Prado, 2003).

\section{DISSERTAÇÕES E TESES}

Acima já foi destacado o grande investimento do grupo da UERJ no estudo do pentecostalismo. Não é de espantar, portanto, que o mesmo se verifique nas teses e dissertações dos estudantes. A primeira dissertação do programa como um todo, defendida em agosto de 1997, foi sobre pentecostalismo, orientada por Patrícia Birman: A linguagem do funkeiro inovações e estratégias conversionistas em igrejas neo-pentecostais no Rio de Janeiro, de Márcia Leitão Pinheiro (atualmente professora na Universidade do Estado do Norte Fluminense - UENF). Como essa, as outras três dissertações defendidas logo a seguir naquele ano, e também em 1998, tinham como tema o pentecostalismo. Foram elas: Ritos do Reino de Deus: pentecostais e inserção ritual (de Patrícia Guimarães, orientada por Patrícia Birman), Conversãoreligiosade detentos, um estudosobre um processo de conversão 
religiosa no contexto carcerário (de EdigarAmorim,orientadapor Cecília Mariz) e em 1998, Demônios do Reino de Deus: a Igreja Universal do Reino de Deus na Argentina (de Patrícia MariaCosta Moreira,orientada por PatríciaBirman). Esses trabalhos focavam especialmente as rupturas e continuidades entre o pentecostalismio e a sociedade brasileira mais ampla. Também focava o pentecostalismo, a dissertação $O$ show da Fé: Carisma e Mídia na Igreja Internacional da Graça de Deus, por Joseane Cabral da Silva, orientada por Márcia Leite, em 2005.

O estudo sobre pentecostais também reaparece quando a temática mais ampla é o universo evangélico, como foi o caso de duas dissertações: a de Maria Goreth dos Santos, A mulher na hierarquia evangélica: o pastorado feminino, defendida em março de 2002, e Marcela Serrano, Sem forró e sem Peixeira: O nordestino como a "palavra", defendida em dezembro de 2004, ambas orientadas por Cecília Mariz. Esse último trabalho se concentrou em fiéis da Assembléiade Deus, igreja que mais atraia os nordestinos pesquisados em Rio das Pedras, campo dessa dissertação. Por seu lado, Maria Goreth observaque há mais mulheresnas igrejaspentecostais,especialmente naquelas pequenas igrejasfundadas por mulheres. Como o trabalho de EdigarAmorim, essasduas dissertaçõesforam pesquisas qualitativas, que procuravam relacionar o pentecostalismo com outrasquestõesnão religiosas:violênciae crime(Edigar Amorim), gênero (Maria Goreth dos Santos) e migração (Marcela Serrano).

Devido a sua especialidade nos estudos dos evangélicos, Clara Mafra foi convidada a co-orientar uma dissertação de mestradoe uma tese de doutorado desenvolvidas em outras pós-graduações, como foi o caso da dissertação de Marcelo Natividade Carreiras Homossexuais e Pentecostalismo, cuja ênfase recaiu sobre estudo de pentecostais e foi defendida em 2003 no Instituto de Medicina Socialda UERJ,e o trabalho de MônicaRolo, Itineráriosterapêtuticos de mães portadorasde malformação congênita, tese que se encontra na fronteira entre antropologia da religião e medicina e que foi defendida na ENSP/ Fiocruz, em 2005.

Dentro do campo do pentecostalismo a Igreja Universal, em especial, inspirou reflexões das teses e dissertações. A primeira tese de doutorado em religião, A Era das Catedraisda IURD: a autenticidade em exibição, de Edlaine 
de Campos Gomes (orientada por Márcia Contins), defendida em 2004, era sobre essa igreja. Também investigavam a IURD as dissertações de Patrícia Guimarães, Patrícia Moreira, já citadas, bem como a dissertação de Cláudia Wolff Swatowiski (orientada por Clara Mafra), Igreja Universal na Capital Nacional do Petróleo: Considerações sobre as dinâmicas da comunicação de massa a serviço de Deus, defendida em 2006.

Por um lado, a Igreja Universal chama atenção por sua relação com as religiões afro-brasileiras, combate e troca com elas. Ocorreria aí um novo tipo de sincretismo? Como essa igreja brasileira se implanta em outros países? Por outro lado, a Universal amplia sua presença no espaço público através da mídia, da política e, mais recentemente, pela construção das catedrais. A forte presença da Igreja Universal na cidade do Rio de Janeiro, seu rápido crescimento, que culminou na eleição de um senador por esse Estado, pode explicar esse interesse especial. Mas o interesse acadêmico pela Igreja Universal vai para além das fronteiras do Rio de Janeiro, como se nota no levantamento realizado por Oro, Corten e Dozon (2003).

Embora ainda se observe queda no percentual dos que se declaram católicos, o que vai despertar interesse de pesquisa no campo do catolicismo nos 1990 no Brasil serão as transformações nas práticas e discursos desses fiéis. Paralelamente ao intenso crescimento do Movimento de Renovação Carismática Católica,a Igreja da Libertaçãorevê seusprojetose procura diálogo com correntes mais místicas. Essas mudanças, contudo, não implicam uma saídado catolicismoda esferapública,como mostram as diferentes dissertações e teses defendidas sobre catolicismo nesse grupo de pesquisa.

Até 2007, quatro dissertações e duas teses de doutorado se inspiraram no catolicismo. A dissertação de Sílvia Regina Alves Fernandes, "Vinho Novo em Odres Velhos?" Uma análise da religiosa feminina na modernidade contemporânea, analisa uma questão relativamente pouco estudada: a vida religiosa feminina. A autora compara quatro tipos distintos de congregação religiosa e discute dilemas e crises desse tipo de vocação na sociedade contemporânea. Já as três outras dissertações, a de Rozicléa Nascimento, Projetode integração comunitária: a crise de um grupo católicoprogressista no Rio de Janeiro, defendida em 2000, Um mergulho no Espírito de Deus: Diálogos

Debates do NER, Porto Alegre, ANo 8, N. 11, P. 21-48, JAN./Jun. 2007 
(im)possíveis entre a RCC e a Nova Era na Comunidade de Vida no Espírito CançãoNova, de ElianeMartins de Oliveira, defendida em 2003,e Da mística à utopia: um estudo antropológico do movimento Mística e Revolução por novas reflexões sobre Juventude, Religião e Política, de Paulo Cézar Batista, defendida em 2005, tratam mais diretamente das mudanças no catolicismo descritas acima. Enquanto essa última foi orientada por Patrícia Birman, as três primeiras foram orientadas por Cecília Mariz.

Comojá foi dito,essas transformações no catolicismotambém inspiraram duas teses de doutorado Experiências religiosas - Um Estudo sobre Mística e Autonomia nos discursose práticas de católicos da Libertação e ca tólicos carismáticos" de Andréa Damacena Martins (defendida em 2004) e "Ser padre para ser santo"; "Ser freira pra servir". A construção social da vocação religiosa - uma análise comparativa entre rapazes e moças no Rio de Janeiro, de Sílvia Regina Alves Fernandes (também de 2004), orientadas por Cecília Mariz. Nesses trabalhos,nota-se uma trocacom as ONGsna medidaque ambasdoutorandas tiveram experiência de pesquisa no CERIS.

Os trabalhos dos estudantes desse grupo de pesquisa estão em consonância com as pesquisas realizadas pelos professores, tanto no campo do pentecostalismo como no catolicismo. O catolicismo é uma área de pesquisa importante, desenvolvida por Cecília Mariz desde sua tese de doutoramento quando pesquisava Comunidades Eclesiais de Base (CEBs), e depois a partir de 1992, quando passou também a estudar o movimento carismático. Também Sandra Carneiro, em sua pesquisa sobre o Caminho de Santiago e outras rotas de peregrinação brasileiras, reflete sobre uma nova sensibilidade religiosa entre católicos das classes médias no Brasil.

A escolha da temática,desta forma, depende dos eventos e características do campo religioso, mas também das trajetórias e experiências pessoais. Observamos, na análise dos que pesquisaram catolicismo em suas teses e dissertações, uma inserção anterior em um catolicismo libertador. Em suas pesquisas sobrecatolicismo, essesmestres e doutores trataram, de algummodo, sobre a crise dessa religiosidade politizada e o surgimento de novas práticas sejam essas carismáticas ou outras. 
A experiência em ONGs parece ter marcado a trajetória de vários estudantes. Edigar Amorim, por exemplo, escolheu trabalhar com pentecostais no cárcere a partir de umapesquisano ISERcom LuisEduardoSoares,também professordo PPCIS. Também teve experiência no ISER, a mestranda Rozicléa Nascimento, que foi orientada na monografiade graduaçãoe Iniciação Científica na UFRJ por Regina Novaes. A troca entre ONGs e pós-graduação ainda permanece.

As religiões afro-brasileiras foram as que menos inspiraram pesquisas durante o período analisado, apesar de duas professoras, Patrícia Birman e Márcia Contins, terem grande investimento de pesquisa nesse grupo na década de 1980. No PPCIS, apenas duas dissertações sobre religiões afrobrasileiras, ambas orientadas por Patrícia Birman, foram defendidas: "Tá na hora de você pedir": uma foto-etnografia sobre a experiência da incorporação em terreiro de umbanda (de Adriana dos Santos Fernandes), em 2001, e Caçadores de utopia: construções de identidades e associações entre religião $e$ política no Rio de Janeiro, de Luiz Fernandes de Oliveira, em 2002.

Religiões orientais e outras práticas vinculadas ao que se tem chamado de Nova Era foi o tema de três dissertações de mestrado e uma tese de doutorado. Entre as dissertações, temos: Modernidadee globalização religiosa: "Nova Era" no Rio de Janeiro/Brasil e San Sebastián/Espanha, de Maria Lúcia Tauil Bernardo, orientada por Cecília Mariz e defendida em julho de 1999, OM SAI RAM: Encontros e trânsitos no campo religioso brasileiro, de Alberto Calil Elias Junior, orientada por Patrícia Birman, de 2004, e A busca de jovens: participação e pertencimento da juventude messiânica a partir do Johrei Center Andaraí, de Maurício França Fabião, em 2005, orientada por Márcia da Silva Pereira Leite. Por fim, uma tese de doutorado tratou desse tipo de religiosidade: "Imagine se tudo isso for verdade": o Movimento Raeliano entre cidades, nações e religióes da modernidade, de Carly Barboza Machado (orientada por Patricia Birman), defendidaem outubrode 2006. Tendo como objeto de pesquisa um grupo considerado como uma seita internacional, o estudo de Carly dialoga com a pesquisa de sua orientadora sobre seitas na França (Birman, 2000 e 2005b).

Debates do NER, Porto Alegre, ANo 8, N. 11, P. 21-48, JAN./Jun. 2007 
Ainda sobre o tema religião, mas sem focar sobre um grupo específico, temos a dissertação de mestrado de Ana Cecília Pacheco, Espiritualidade na escola: afetos, palavra, silêncios. Uma etnografia de um estudo "não convencional", também orientada por Patrícia Birman e defendida em 2002.

No entanto, como já foi dito antes, os professores desse grupo de pesquisa têm orientado trabalhos que não são necessariamente vinculados à religião. Entre esses, se observa que os temas privilegiados têm sido violência (como a tese Violência e identidade social: um estudo comparativo sobre a atuação policial em duas comunidades do Rio de Janeiro, de Jorge da Silva, orientado por Márcia Contins, defendida em 2005, e a dissertação Tragédia e Acomodação: uma análise antropológica do assassinato do jornalista Tim Lopes de Robson de Paula, orientada por Clara Mafra, defendida em 2004), meio ambiente (a tese $O$ processo ambientalizador e a etiqueta ambiental da empresa que "pensa verde": o caso da Companhia Siderúrgica Nacional, de Silvia Borges Corrêa, defendida em 2006, e as dissertações Participação sociopolítica na gestão ambiental da reserva extrativista da Marinha de Arraial do Cabo, de Marcus Machado Gomes, de 2005, e Tem meio ambiente na favela? Ambientalismo na Serra da Misericórdia, de Eduardo Simas, de 2007, todas orientadas por Rosane Prado). Além de trabalhos sobre outros movimentos sociais, como o MST (o caso da dissertação Cultivando identidades: a semente crioula e a invenção do camponês na "Campanha das Sementes" do MST, de Cecília Moreyra de Figueiredo, defendida em 2006 e orientada por Márcia Leite), movimento negro (a tese Para além do racismo e do anti-racismo: a produção de uma Cultura de Consciência Negra na sociedade brasileirade AmauriMendes Pereira, de 2006, orientada por MárciaContins), e outros movimentos sociais (a dissertação TrabalhoVoluntário:considerações sobre dar e receber, de Andréa Freitas da Silva, orientada por Márcia Contins, defendida em 2006). Outra temática observada foi cultura popular (a tese Estrada da Vida: a organização do mundo dos rodeios no Brasil, de Simone Pereira da Costa, de 2003, e a dissertação $A$ feira e o shopping de cultura popular, de Ruth Helena de Souza Britto, de 2002, ambas orientadas por Patrícia Birman). 


\section{CONSIDERAÇÕES FINAIS}

Por fim, gostaríamos de destacar que esse grupo de pesquisa busca compreender a religião no mundo globalizado e, para isso, vários membros do grupo, tanto professores quanto alunos, têm tido experiência de pesquisa de campo fora do Brasil. Antes de entrar na UERJ, em sua tese de doutoramento, Márcia Contins comparouos pentecostais negros norte-americanos com brasileiros, tendo várias publicações sobre o tema (ver Contins, 2004b). Também em sua tese de doutorado, Clara Mafra realizou uma comparaçãointernacionalda IgrejaUniversal no Brasile em Portugal. Patrícia Birman, por sua vez, em 2000 defendeu sua tese de professora titular baseada em pesquisa na França sobre o movimento anti-seitas, com o objetivo de pensar as diferenças de atitudes francesas e brasileiras em relação à religião e laicidade. Estudantes também se motivam para realizar pesquisas em outros países, projetos até muito recentemente considerados inapropriados ou inviáveis no Brasil. A tese de doutorado de Carly Machado aborda a rede internacionalraeliana, tendo paraisso realizado pesquisa na Europae no Brasil. Outro exemplo é a tese de Amanda Dias, co-orientada por Patrícia Birman, que está sendo desenvolvida na EHESS e na UERJ. Esse estudo compara um campo de refugiados palestinos com a favela carioca de Acari, discutindo, entre outras coisas, a violência e a religião.

Duas dissertações de mestrado tratam de comparações internacionais. Embora no caso dessas duas dissertações a decisão de realizar esse tipo de comparação possa ser explicada pelas trajetórias pessoais das autoras, pensar nesse tipo de comparação,a mobilidadepara realizá-la,bem como as próprias trajetórias pessoa is internaciona is, nos mostram como a globalização ampliou as fronteiras de nosso cotidiano. A orientação pode ser feita por $e$-mail e as passagens ficaram mais baratas; entretanto, sem apoio para pesquisas internacionais no mestrado, elas aconteceram pela própria globalização da vida cotidiana e das relações pessoais. Destacamos ainda as experiênciasde troca internacionais duas alunas de doutorado que realizaram um período de estágio na Vrije Universiteit de Amsterdam VUA (Andréa Damacena Martins, em 2001, e Carly Barbosa, em 2005).

Debates do NER, Porto Alegre, ANo 8, N. 11, P. 21-48, JAN./Jun. 2007 
É importante lembrar que várias pesquisadoras do grupo integram com suas pesquisas o projeto Movimentos Religiososno Mundo Contemporâneo do Programa de Apoio aos Núcleos de Excelência (PRONEX), edital de 1998, que reuniu pesquisadores da UFRGS, UnB, USP e UFRJ (IFCS e Museu Nacional), sob coordenação geral do professor Dr. José Jorge de Carvalho (UnB). Esta linha de pesquisa teve uma interface com o Núcleo de Antropologia e Imagem da UERJ, que propicia o desenvolvimento de uma Antropologia e de uma Sociologia da Imagem, da Mídia e do Cinema, associadas ao campo da religião e dos movimentos sociais. Neste âmbito, realiza programas de extensão relacionados a movimentos de favelas e movimentos ecológicos, bem como à produção de instrumentos de linguagem visual.

\section{REFERENCIAS}

BIRMAN, Patrícia. Cultos afro-brasileiros ou como falar de nação, gênero e etnicidade falando de religião? Não-publicado, 2007.

. O EspíritoSanto, a mídia e o território d os crentes. Cienciassociales y religión/Ciências sociais e religião, v. 8, p. 41-62, 2006.

Fronteiras espirituais e fronteiras nacionais: o combate às seitas na França. Mana, Rio de Janeiro, v. 11, p. 7-39, 2005a.

. Transas e transes: sexo e gênero nos cultos afro-brasileiros, um sobrevôo. Estudos Feministas, Florianópolis, v. 13, n. 1, 2005 b.

(Org.). Religião e Espaço Público. Rio: Attar, 2003.

___ - Religiosidade, pluralismo e nação: as seitas na França hoje. Tese (Concurso para Professor Titular em Antropologia) - UERJ, 2000.

BIRMAN, P.; LEITE, M. P. (Org.). Um Mural para a Dor: Movimentos cívico-religiosos por justiça e paz. Porto Alegre: UFRGS/Pronex, 2004.

BIRMAN, P. LEITE, M.; CARNEIRO, S. Entre a política e a religião: experiências e trajetórias de cientistas sociais da geração 68/70. Numen, Juiz de Fora-MG, v. 7, n. 1, p. 81-104, 2004. 
CAMURÇA Marcelo A. Da "boa" e da "má" vontade para com a religião nos cientistassociais da religião brasileiros. Religião \& Sociedade, Rio de Janeiro, v. 21, n.1, p. 67-86, 2001.

CARNEIRO,Sandra de Sá. Religião nas escolas públicas: questões nacionais e a situação no Rio de Janeiro. Revista Contemporânea de Educação, Rio de Janeiro, n. 02, p. 01-03, 2006.

Novas peregrinações brasileiras e suas interfaces com o turismo. Ciencias sociales y religión/Ciências sociais e religião, Porto Alegre, n. 6, p. 71100, 2004a.

Pesquisa via Internet: desafios e perspectivas do trabalho antropológico. Cadernos de Antropologia e Imagem, v. 18, n. 1, p. 189-210, 2004b.

___ Rumo a Santiago de Compostela: os sentidos da peregrinação moderna. Tese Doutorado em Antropologia - IFCS/UFRJ, 2003a.

Caminhos de Santiago de Compostela: percurso, identidade e passagens. In:BIRMAN,Patrícia.(Org.). Religião e EspaçoPúblico.São Paulo: Attar, 2003b, p. 259-281.

CARNEIRO, S.; FREIRE-MEDEIROS, B. Antropologia,religião e turismo: múltiplas interfaces. Religião \& Sociedade, v. 24, p. 100-125, 2005.

CONTINS, Márcia; GOMES, Edlaine de Campos. Os Percursos da Fé: uma análise comparativa sobre as apropriações religiosas do espaço urbano entre pentecostais e carismáticos. Revista do Núcleo de Antropologia Urbana da USP/Ponto Urbe, São Paulo, v. 1, 2007.

CONTINS, Márcia. Os Pentecostais e as Religiões Afro-Brasileiras. Textos escolhidos de cultura e arte populares, Rio de Janeiro, v. 2, p. 37-50, 2005a.

___ Lideranças Negras. Rio de Janeiro: FAPERJ/Aeroplano, 2005b.

———. Objetivos e Estratégi as da Ação Afirmativa: uma bibliografia. BIB.

Revista Brasileira de Informação Bibliográfica em Ciências Sociais, São Paulo, n. 57, p. 91-102, 2004a. 
CONTINS,Márcia.Subjetividadee Alteridade:os pentecostaisnegrosno Brasil e nos Estados Unidos. Logos, Rio de Janeiro, v. 11, n. 21, p. 150-174, 2004b.

FERNANDES, Rubem César; VELHO, Otávio; SANCHIS, Pierre; CARNEIRO, LeandroP.; MARIZ,Cecília; MAFRA,Clara. NovoNascimento - os evangélicos em casa, na igreja e na política. Rio de Janeiro: Ed. Mauad, 1998.

. Censo Institucional Evangélico CIN 1992 - Primeiros Comentários. Textos de Pesquisa. Rio: ISER, s/d.

LANDIM, Leilah. "Experiência militante": histórias das assim chamadas ONGs. In: Ações em sociedade - militância, caridade, assistência, etc. Rio de Janeiro: ISER/NAU, 1998, p. 23-89.

LEITE, Márcia Pereira. Religião e política no espaço público: movimentos de moradores de favelas contra a violência e por justiça. In: ALMEIDA, Ronaldo de; MAFRA, Clara. (Org.). Religióes e Cidades: Rio de Janeiro e São Paulo. São Paulo: CEM/CEBRAP e Pronex/CNPq, 2007 (no prelo).

___ D Dádiva e missão entre familiares e vítimas de violência. In: MARTINS, Paulo Henrique; CAMPOS, Roberta Bivar (Org.). Polifonia do Dom. Recife: Editora Universitária UFPE, p. 165-208, 2006a.

Na tela o povo e a nação: classes populares e periferias em imagens. In: FREIRE-MEDEIROS, Bianca; COSTA, Maria Helena (Org.). Imagens Marginais. Natal: Editora da UFRN, 2006b, p. 39-56.

___ . The favelas of Rio de Janeiro in Brazilian cinema (1950 to 2000). In: VIEIRA, Else R. P. (Org.). City of God in Several Voices: Brazilian Social Cinema as Action. Notting ham, CCCP: Critical, Cultural and Communications Press, 2005, p. 149-165.

MACHADO, Mariadas DoresCampos; MARIZ,Cecília.Religião, mulheres e política institucional: evangélicas e católicas. In: SOUZA, Sandra Duarte de. (Org.). Gênero e religião no Brasil: Ensaios feministas. São Bernardo do Campo - SP: Universidade Metodista de São Paulo, 2006, p. 45-68.

MAFRA, Clara C. J. Os Evangélicos. Rio de Janeiro: Jorge Zahar, 2001. 
MAFRA, Clara C. J. Na Posse da Palavra Lisboa: Imprensa de Ciências Sociais - Universidade de Lisboa, 2002.

-_- Jesus Cristo Senhor e Salvador da Cidade - Imaginário Crente e Utopia Política. Dados, Rio de Janeiro, v. 49, p. 583-614, 2006.

- Casa de Deus, Casa dos Homens. Análise Social, Lisboa, v. 182, p. 145-161, 2007.

MAFRA, Clara; SWATOWISKI, Cláudia. O balão e a catedral - trabalho, lazer e religião na paisagem carioca. Anthropológicas, Recife, 2007 (no prelo).

MARIZ, Cecília Loreto. La enseñansa y la investigación en la sociología de la religión en Brasil. In: FRIGERIO, Alejandro (Org). Ciencias sociales y religión en el Cono Sur. Buenos Aires: Centro Editor de America Latina, 1993, p. $72-85$.

Comunidades de vida no Espírito Santo: juventude e religião. Tempo Social, São Paulo, v. 17, n. 2, p. 253-274, 2005.

Catolicismo no Brasil Contemporâneo: Reavivamento e Diversidade. In: TEXEIRA, Faustino; MENEZES, Renata (Org.). As Religiões no Brasil: Continuidades e Rupturas. Petrópolis: Vozes, 2006, p. 53-68.

MARIZ, Cecília; MACHADO, Maria das Dores; DROGUS, Carol Ann; STEWART-GAMBINO, Hannah. Catholics and Pentecostals: Possibilities for Alliance. In: DROGUS, Carol Ann; STEWART-GAMBINO, Hannah. (Org.). Activist Faith: Grassroots Women in Democratic Brazil and Chile. University Park:The Pennsylvania State University Press, 2005, p.129-153.

MARIZ, Cecília; PERES, Vitória. Conversion to Islam in Contemporary Brazil. Exchange, The Netherlands, v. 35, n. 1, p. 102-115, 2006.

NOVAES, Regina. Religião e Sociedade, vinte anos: entrevista com Rubem César Fernandes. Religião \& Sociedade, Rio de Janeiro, v. 18, n. 2, p. 7-28, 1997.

ORO, Ari Pedro. El estudio de la religión desde las ciencias sociales en el Brasil. In: FRIGERIO, Alejandro (Org.). Ciencias Sociales y religión en el Cono Sur. Buenos Aires: Centro Editor de America Latina, 1993, p. 86-92. 
ORO, Ari Pedro; CORTEN, André; DOZON, Jean-Pierre (Orgs). Anexo: Teses e dissertações sobre Igreja Universal do Reino de Deus defendidas no Brasil e no exterior. In: Igreja Universal do Reino de Deus - os novos conquistadores da fé. São Paulo: Paulinas, 2003, p. 365-379.

PRADO, Rosane. Crentes na Ilha Grande: uma forma de ser nativo. In: BIRMAN, Patrícia (Org.). Religião e Espaço Público. São Paulo: Attar Editorial/CNPq/Pronex, 2003, p. 123-146.

(Org.). Ilha Grande: do sambaqui ao turismo. Rio de Janeiro: EdUERJ, 2006a.

Depois que entrou o IBAMA: percepção de questões ambientais na Ilha Grande. In:PRADO,Rosane Manhães (Org.). Ilha Grande.do sambaqui ao turismo. Rio de Janeiro: EdUERJ, 2006b.

PRADO, Rosane Manhães; SANTOS, Myrian Sepúlveda dos. (Org.). Coleção Ilha Grande. Rio de Janeiro: EdUERJ, 2003.

REYESHERRERA, SoniaE. Reconstruçãodo Processo de Formação e Desenvolvimento da Área de Estudos da Religião nas Ciências Sociais. Tese (Doutorado em Sociologia) - PPGS/UFRGS, Porto Alegre, 2004.

SANCHIS, Pierre (Org.). Catolicismo: Modernidade e tradição. São Paulo: Loyola, 1992a. 1992b.

(Org.). Catolicismo: Cotidiano e movimentos. São Paulo: Loyola,

(Org.). Catolicismo: Unidade religiosa e pluralismo cultural. São Paulo: Editora Loyola, 1992c.

THEIJE,M.; MARIZ,C. L. Localizing and GlobalizingProcesses in Brazilian Catholicism: Comparing Inculturation in Liberationist and Charismatic Catholic Cultures. Latin American Research Review (LARR), Austin, v. 43, n. 1, 2008 (no prelo).

VELHO, Otávio. Trabalhos de campo, antinomias e estradas de ferro. Interseções, Rio de Janeiro, ano 8, n. 1, p. 9-27, 2006. 
ESTUDOS SOBRE RELIGIÃO NA PÓS-GRADUAÇÃO EM CIÊNCIAS SOCIAIS...

VELHO, Otávio. [1987]1995. O cativeiro da Besta Fera. Besta-Fera Recriação do Mundo.Rio de Janeiro: Relume-Dumará,[1987]1995, p. 13-44. 
ANEXO: Temas das teses e dissertações sobre religião orientadas pelo grupo Religião e Movimentos Sociais - PPCIS/UERJ.

\begin{tabular}{lc}
\hline \multicolumn{1}{c}{ Temas } & Defesas \\
\cline { 2 - 2 } & Quantidade \\
\hline Pentecostalismo & 8 \\
Catolicismo & 6 \\
Novos Movimentos Religiosos e Nova Era & 4 \\
Religiōes Afro & 2 \\
Religiä́o escola grupos & 1 \\
Total & 21 \\
\hline
\end{tabular}

Recebido em 07/07/2007. 